With sudan black the fibres of muscles $135 b, d$ and $e$ stsin darker than those of muscles 136 and 137, moreover, with methylene blue the reducing capacity of $135 b, d$ and $e$ is stronger than that of 136 and 137 . As was the case with Type $A$, the nuclei of this type are situated in the layer of protoplasm right under the sarcolemma. Occasionally, however, they may be found nearer the centre of the fibre.

Muscles $135 a$ and $c$ do not slways give the same picture as 136 and 137 ; generally these are identical, but in some cases there is a closer resem. blance to $135 b, d$ and $e$. This phenomenon was observed especially after fixation in Bodian 2.

According to Becht and Dresden ${ }^{2}$ the muscles 136, 137 and $135 a$ and $c$ are fast-contracting, and $135 b, d$ and $e$ slow-contracting. The observations described above show that in frozen sections both the slow and the fast muscles are of Type $A$, whereas in paraffin sections the fast muscles are for the greater part of Type $A$, but the slow muscles are always of Typo $B$. This difference can be explained only in terms of a different reaction with the fixation liquids, alcohol, methyl benzoate, benzol and paraffin.

This seems to indicate a difference in physicochemical composition that causes the slow musoles to shrink more under the influence of the fixation liquids than the fast ones and that also causes the radial arrangement of the sarcostyles to be lost. Moreover, it is evident that the fibres of the slow muscles contain more lipoids and water and have a stronger reducing capacity than the fibres of the fast muscles.

W. A. SMIT

Zoological Laboratory,

University of Amsterdam. Dec. 17.

1 Pringle, J. W. S., J. Exp. Biol., 16, 220 (1939).

- Becht, G., and Dresden, D., Nature, 177, 836 (1956).

- Krüger, P., "Tetanus und Tonus der Quergestreiften Skelettmuskeln der Wirbeltiere und des Menschen" (1952).

- Carbonell, C. S., Smith. Misc. Coll., 107, No. 2 (1947).

\section{Masculinizing Action of Pregneninolone on Female Gonads in the Cyprinodont, Lebistes reticulatus $\mathbf{R}$.}

Several authors have tried to induce sex inversion in Lebistes reticulatus experimentally by the use of sex hormones. Berkowitz ${ }^{1}$ found that a high percentage of males treated from birth with ostrogenic substances developed ovotestes. The expected result with androgenio hormones would be the production of ovotestes in treated females. Treating young from birth, for a prriod of two to three months, Eversole $^{2}$ and Gallien ${ }^{3}$ arrived separately at the same conclusion: that pregneninolone causes the ovaries to undergo a considerable regression, but that they always keop their female structure. Gallien added that after the cessation of treatment the ovaries returned to normal.

Suspecting that their failure to produce masculinization of the gonads was due to the relatively short duration of their experiments, and to the excessively high dose of pregneninolone used, we have carried out the following experiment : 55 animals, all the same brood of Lebistes, were treated from birth for a period of 6 months. Treated animals were divided into two groups : the first was given a high dose of $0.03 \mathrm{mgm}$. of pregneninolone (Ethistérone, UCLAF), thre日 times a week. The second received a low dose of $0.015 \mathrm{mgm}$. of the same hormone, thrice weekly.
A third group of control animals was raised in a manner identical with the treated ones. At the end of the experiment, histological examination of gonads showed that out of 55 treated animals, 37 were males, 15 possessed hermaphrodite gonads and 2 were typical females. Out of 16 control fish, we found 11 males and 5 females.

All treated animals, regardless of sex, showed a transformation of the anal fin into a more or less typical gonopodium. Gonopodis of treated animals were shorter than those of the control ones, and those of the high-dose group were shorter than those of the low-dose group. Specific characters of the gonopodium were present (that is, ventral and dorsal spines, as well as the terminal hook). There were not so many in treated fish as in the controls. Terminal bifurcations, normally found in both sexes, on the fourth, fifth and sixth rays of the anal fin, were partially or completely absent in treated animals. Treatment inhibited growth to a great extent, in both sexes. While treated males had typical body colorations, females had few, if any, body pigments, and when present they were very pale.

The first hæmal spine persisted in all treated animals except one; normally this regresses in both males and femsles, 4 , This spine has the same morphology as the following hæmal spines. In almost all treated animals, the gonactines (interhæmal spines) have normal male morphology; in the others the gonactines are completely welded together.

The chronology of development between different secondary sexual characters is disturbed in many cases, due to an acceleration in the development and differentiation of the gonopodium with regard to internal suspensorial elements.

Treated males have testes more or less normal in structure, but in the high-dose group there is an obvious stimulation of spermatogenesis, in such a way that late stages predominate. Sperm ducts are more numerous than in control testes, and their epithelium seems to be highly stimulated.

Gonads of all treated animals, presumed to be genetic females (except two), are transformed into ovotestes. These gonads show different degrees of masculinization. Male elements existing include cysts of spermatogonia, spermatocyte I and II. Cysts of spermatids are less numerous, and spermatophores are rare; whenever present, these are abnormal in structure. In the ovotestes, a certain number of tubules can be distinguished, probably deriving from the epithelium of the ovarian cavity. These tubules are the homologues of sperm-ducts in female gonads. The oranial region of gonads seems to be more sensitive to the masculinizing action than the posterior region, which sometimes maintains its typical ovarian aspect. In most cases, the persisting ovarian cavity is much expanded. Besides these male elements, and side by side with them, eysts of oogonia, and ovules at different stages of development, can be distinguished. Fully mature ovules are exceptional. Atrophied follicles appear here and there in the gonad.

Laboratoire de Zoologie et

T. MOHSEN

d'Embryologie expérimentale,

Université de Strasbourg.

Deo. 2.

${ }^{1}$ Berkowitz, Ph., J. Exp. Zool., 87, 233 (1941).

' Eversole, W., Endocrinol., 28, 603 (1941).

'Gallien, L., C.R. Acad. Sci., Paris, 228, 52 (1946).

"Mohsen, T., Proc. Egypt. Acad. Sci., 11, 67 (1955).

sohsen, T., C.R. Soc. Biol., 149, 2232 (1955). 